It therefore appears that the absolute alcohol of Mendeléeff was just as pure and free from water as that obtained by the most modern methods.

\title{
Summary.
}

It is demonstrated that the absolute alcohol, prepared by the use of calcined marble and freed from aldehydes, has the same density, the same refractive index and the same critical temperature of solution as that which has been dried by the use of magnesium amalgam or of metallic calcium.

The observations of Crismer, to the effect that the critical temperature of solution of alcohol in kerosene is the best criterion of the dryness of absolute alcohol, is fully confirmed.

Absolute alcohol was found to have the following constants:

Density ${ }_{4}^{\circ 5^{\circ}} 0.78510 \pm 0.00001$.

Zeiss immersion refractometer, $85.30^{\circ}-0.02$ at $25^{\circ} \mathrm{H}$.

Index of refraction ( $\mu$ ) against air, $1.3594 \mathrm{I} \ldots 0.00001$ at $25^{\circ} \mathrm{H}$.

Refractive power ${ }_{d}^{n_{\mathrm{D}}-\mathrm{I}}=0.4583 .3 ;{ }_{d}^{\mu_{\mathrm{D}}--1}=0.45779$.

A table is presented of the refractive indices against air and of the refractometer readings of aqueous alcohols for each per cent. of water from o to 30 , accompanied by an approximate table of temperature coefficients of refraction through the same range.

The existence is demonstrated of a maximum refractive index of 1.3633 I 5 at $25^{\circ}$ for the mixture containing 20.7 per cent. of water and 79.3 per cent. of alcohol, a composition which very closely corresponds by chance or otherwise, with the formula ${ }_{3} \mathrm{C}_{2} \mathrm{H}_{6} \mathrm{O} \cdot 2 \mathrm{H}_{2} \mathrm{O}$ (calculated, 20.69 per cent.).

ST. LOUIS, Missorri.

[CONTRIBLTIONS From the HAVEMEYer LABORATORIES OF Columbia UNiversity, No. I49.]

\section{THE WEIGHT OF A FALLING DROP AND THE LAWS OF TATE. THE DETERMINATION OF THE MOLECULAR WEIGHTS AND CRITICAL TEMPERATURES OF LIQUIDS BY THE AID OF DROP WEIGHTS. ${ }^{1}$}

l3y J. I. IVINGSTUN R. MORGAN AND RESTON STENENSON. Received IJecember $26,1907$.

\section{Introduction. Object of the Investigation.}

In 1864, Thomas Tate," as the result of his experiments with water, announced the following laws:

1 Extract from the Dissertation of Reston Stevenson. Our thanks are due to Mr. E. Higgins for kind assistance in the latter part of the work.

Plill. Mag., 4th Ser., 27, 176 (1864). All other references to drop weight will be found in the bibliography of that subject at the end of this paper. 
I. Other things being the same, the weight of a drop of liquid (falling from a tube) is proportional to the diameter of the tube in which it is formed.

II. The weight of the drop is in proportion to the weight which would be raised in that tube by capillary action.

III. The weight of a drop of liquid, other things being the same, is diminished by an augmentation of temperature.

Tate's experiments were all made with thin-walled glass tubing, varying in diameter from 0.1 to 0.7 of an inch, the orifice in each case being ground to "a sharp edge, so that the tube at the part in contact with the liquid might be regarded as indefinitely thin." His weights were calculated from the weight of from five to ten drops of liquid, which formed at intervals of 40 seconds, and were collected in a weighed beaker.

Tate's Law, as we know it to-day, is supposed to be a summation of the first two laws of Tate, but it must be said that it attributes to Tate a meaning that he never indicated, and probably never intended. The analytical expression of this faulty law is the familiar

$$
W=2 \pi r \gamma,
$$

where $W$ is the weight of the falling drop, $r$ the radius of the tube on which it forms, and $\gamma$ is the surface tension of the liquid. Of course, Tate's second law shows drop weight to be proportional to surface tension, for the weight of a liquid rising in a tube by capillary action is proportional to surface tension; and his first law shows drop weight to be proportional to the diameter (or radius) of the tube; but he did not even imply that drop weight is equal to the product of the circumference of contact into the surface tension. The real analytical expression of Tate's first two laws, as he actually announced them, in place of the above, should be

$$
W=K_{1} \gamma D
$$

where $K_{1}$ is a constant, and $D$ is the diameter of the tube; or, when the drops are all formed on the same tube (i.e., where $D$ is constant),

$$
W=K_{\gamma},
$$

$K$ being a new constant.

The general result of the work of all other investigatcrs since the time of Tate, on the subject of drop weight, may be summed up best, perhaps, in the words of Guye and Perrot (1903), viz.:

"The law of the proportionality of the weight of a drop to the diameter of the tube is no more generally justified than that of the proportionality of the weight to the surface tension."

"The laws of Tate are not general laws, and, even in the case of static (slowly forming) drops, represent only a first approximation."

It will be seen from these conclusions that Guye and Perrot repudiate not only the form of Tate's law as we know it to-day, but also his first 
two laws in the form that he announced them. It must be said, however, that no investigator has as yet fairly tested Tate's laws, for no one has as yet exactly reproduced 'Tate's conditions. 'ractically all the results thus far obtained have been for drops forming on capillary, instead of on thinwalled tubes; and the effect produced by the "sharp edge" of the dropping tube, as described by Tate, has nerer been even approximately approached, except under such conditions that the results were obscured by other factors (Ollivier, Antonow).

The object of this investigation, which was started by one of us, six years ago, is to test the truth of 'late's law (and especially the second), as he originally stated them, more fairly and with greater accuracy than has hitherto been done, reproducing his conditions in a way that others have failed to do, paying particular attention to the effect of the form of the tip, and excluding those errors which are so apparent in the work of some of the previous inrestigators. And it was hoped that even if Tate's laws were found not to hold rigidly, it might still be possible to employ the temperature coefficient of drop weight of any one liqiud, in a formula similar to that of Ramsay and shields, ${ }^{1}$ in place of their temperature coefficient of surface tension, as a means of ascertaining molecular weight in the liquid state, and the critical temperature.

It may be said here, to anticipate, that the results of our work have proven to be even better than we had hoped, for they have shown that not only molecular weights in the liquid state and critical temperatures, can be calculated just as readily and accurately from the temperature coefficient of drop weight, as fron that of surface tension; but also that the relative surface tensions of various liquids can be found from drop weights, and that, thus found, they agree with those determined by the capillary rise as well as do those by any of the other methods, and almost as well as those for the same liquid by the same method, carried out by different observers. This relation to surface tension is true for the interpolated values of surface tension, and further work, using the actual, experimental values, will probably only show the relation to be even more rigid than this.

\section{Apparatus and Method.}

In order to avoid the complication which might be introduced by the successive formation of several drops, we have measured, throughout our work, the volume of a single drop, for that method, under these conditions, is far more accurate and delicate than any weighing method.

Although, unlike Tate, we have used capillary tips upon which the drop forms, we have so constructed thetn that we might expect to obtain an effect similar to that obtained by 'Tate with the "sharp edge"

${ }^{1}$ Zeit. f. phys. Chem., I2, 431 (1893). 
of his thin-walled tube. Apparently the effect of this "sharp edge" is to delimit the area of the tube upon which the drop can hang, and to prevent the liquid rising upon the outer walls of the tube. The form of tip we have employed in our measurements is shown, in section, in Fig. $\mathbf{I}\left(\mathrm{O}^{\prime}\right)$, both the bottom and bevel being highly polished.

Observation of a tip of this form shows that it behaves exactly as such a one as described by Tate, and that the lower edge of the bevel, just as Tate's "sharp edge," is the limit of the area upon which the drop hangs, provided, of course, that its diameter is less than that of the maximum drop of the liquid with the smallest maximum drop. The liquid forming a drop on this tip does not, under any condition, rise to wet the bevel or walls of the tube as it might on an ordinary one. This effect has also been obtained, during the course of our work, by two other investigators (Antonow and Ollivier), but only by the use of foreign substances, which contaminate the liquid.

The complete apparatus used in our preliminary experiments is shown in section, in Fig. I. $P$ is a translucent porcelain scale, 55 centimeters long, divided into millimeters. $A B$ is a capillary burette of such a bore that I millimeter contains about $0.0003 \mathrm{cc}$. This tube was carefully calibrated with mercury, and a curve prepared, from which the volume between any two scale readings could be found. One end of this burette, $A$, was connected by rubber tubing to the rubber compression bulb $K$. This bulb was so arranged in a screw clamp that the

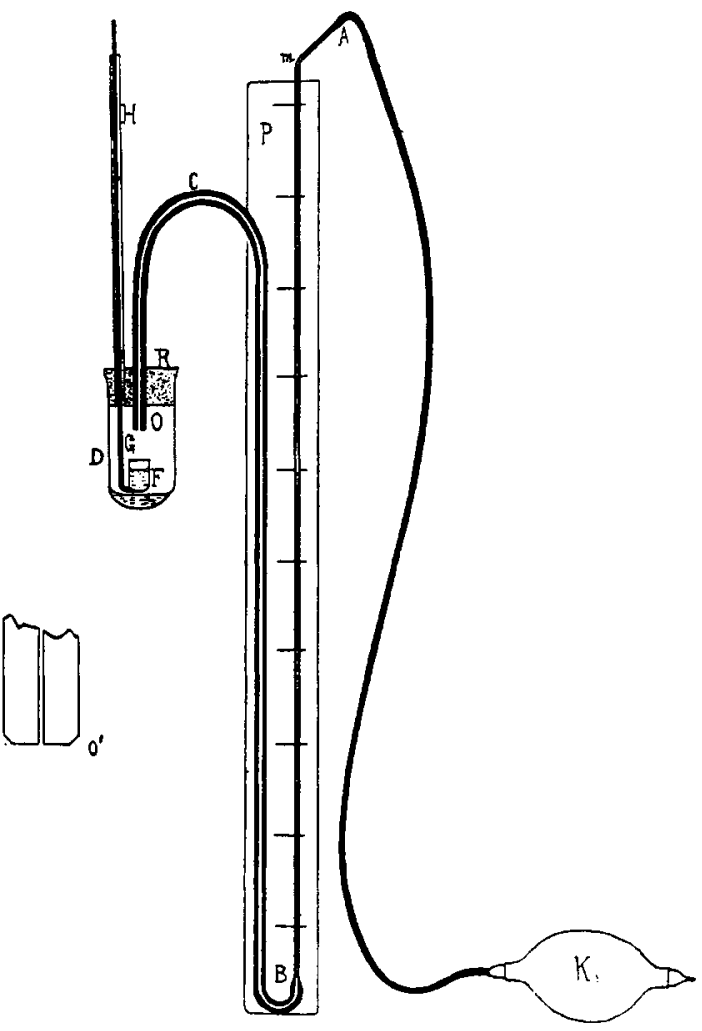

Fig. I. pressure upon it could be gradually increased or decreased, thus giving absolute and delicate control over the movement of the liquid in the burette. The larger tubing $B C$, which is the continuation of the tip, passes through the 
rubber stopper $R$, and thus supyorts the dropping (up $D$ ). F is a dipper which can he raised, lowered, or swung around to any position by means of the $\operatorname{rod} G$. From this the burette can be filled with liquicl, and into it the drop from the tip $O$ ultimately falls. The bottom of the cup $D$ is covered with a thin layer of the liquid, and the tube $H$, through which $G$ passes, is stuffed with filter paper, saturated with the liquicl.

The object of this form of apparatus was to prevent evaporation of the liquid of the drop, and to enable us to measure drop volumes at any desired temperature, by immersing the entire apparatus to the point $m$ in a waterbath.

Before making a measurement with this apparatus, the cup, dipper, tube and tip are thoroughly cleansed with chromic-sulphuric acid, water, alcohol, and ether, and dried by a current of air. The liquid is then placed in the cup and in the dipper, from which, after the stopper $R$ is fastened tightly, the tube is filled to such an extent that the lower meniscus is just about to enter the tip $O$ when the other end of the column (in the burette tube $A B$ ) is at zero, or some point just below it. This point (the zero point) is then recorded, and the bulb very gradually compressed until the drop formed at the tip $O$ falls off. The reading of the other end of the column, at the instant of fall, then enables one, knowing the zero-point, to find the volume of the maximum drop that can form on the tip; we shall designate this as the pendant drop (P. D.). By drawing the liquid, that is left on the tip, back into the tube again, until the lower meniscus is once more just about to enter the tip $O$, it is possible to find the volume of the drop that has remained clinging to $O$; this we shall call the clinging drop (C. D.). Subtracting the volume of this from that of the pendant drop, we finally find the volume of the falling drop ( $\mathrm{F}$. D.).

Experiments with this preliminary apparatus showed the method to be excellent, but made apparent the fact that greater delicacy was desirable. Our second, and final form of apparatus, as shown, in section, in Fig. 2 , is simply a modification of the first. Here the dropping tube is sealed into a glass stopper, and the cup is provided with a wide rim to allow the use of mercury as a seal. An clastic band, passed from the hooks $Q$ orer the stopper, and between the two tubes, holds stopper and cup together, and prevents the passage of either metcury or the water of the bath into the cup. To obtain a more delicate setting, in determining the zero-point, than is possible by observing the passage of the meniscus into the tip, the dropping tube, here, is constricted at .5 , and the lower meniscus, in all readings, is held to a mark at that point.

Two pieces of apparatus in this form were used, the burette in one case (tube 2) holding approximately $0.000,08 \mathrm{cc}$., and the other (tube .3) $0.000,056$ 
cc. per millimeter. ${ }^{1}$ In order that a scale of the same length as before might be used, these measuring tubes were bent in the form shown in Fig.

2. In tube 2 there were three small bulbs blown in the first length of the burette, while tube 3 had a single bulb $V$, with an approximate capacity of $0.027 \mathrm{cc}$. The use of a bulb or bulbs enabled us to get the total volume of liquid necessary for a drop, without an excessive length of the tubing. For liquids forming drops of large volume, the zeropoint must be above the bulb or bulbs; for those giving smaller volumes it must be below the single bulb, or, in case there are three bulbs, below one or more of them.

With these pieces of apparatus, only the volumes of the falling drops were measured, for the results with the first apparatus showed that, of the three kinds of drops, they only were related to surface tension. Our reason for originally determining the volumes of all three kinds of drops, when Tate considered only the falling drop, was the suggestion of Ostwald ${ }^{2}$ that the pendant drop from a capillary tube would probably correspond to falling drop from a thinwalled tube, such as Tate used. Experiment shows, however, that here, also, the falling drop is the important factor.

To measure the volume of the falling drop with this piece of apparatus, the zero-point is found, just as before, by drawing the liquid back into the burette, until, when the

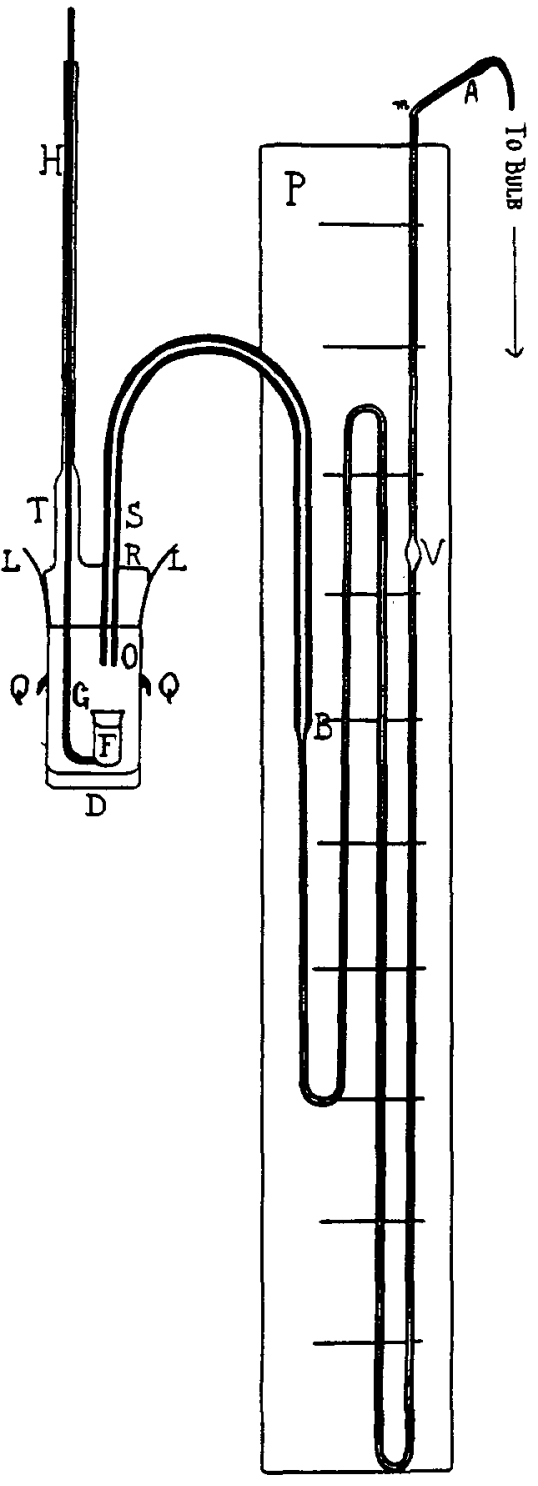

Fig. 2.

1 These tubes were calibrated with mercury at room temperature, and no correction in volume was made when they were used at higher temperatures, for the variations were found to be well within the experimental error.

${ }^{2}$ Hand- und Hilfsbuch zur ausführung Physiko-chemischer Messungen. Leipzig, 1893, pp. 300-301. 
upper meniscus is at zero or just below it, the lower meniscus is exactly at the mark in the constricted portion of the tube $S$; then. as before, the liqiuid is very gradually forced over until the drop on the tip $O$ falls off. No reading for the pendant drop is attempted, but the liquid is at once drawn back to the mark, and, after allowing sufficient time for drainage, the position of the upper meniscus is observed. The difference in volume of the burette tube, between the zero-point and the latter point, is then the volume of the drop that has fallen. The pressure on the rubber bulb in all cases must be increased very gradually at the instant when the drop is about to fall, for a sudden increase in pressure at that time tends to increase the volume of the falling drop.

It was necessary before using these delicate forms of apparatus to prove conclusively that no evaporation takes place from the drop as it is forming. To ascertain this the tube was filled with liquid, and the zero-point noted. Then gradually the pressure on the bulb was increased until a large drop, though not sufficiently large to fall, was formed at $O$. After standing in this condition for several minutes, care being taken, as it must always be, that the apparatus was not jarred or disturbed, the liquid is drawn back until the lower meniscus is again at the i.lark at $S$. Any decrease in volume of the liquid, from that originally observed, is then to be attributed, with such tips as we have used, to evaporation from the drop. Even our first observations for this purpose, however, showed that there was no evaporation, for we invariably found an increase in the volume of the liquid, instead of a decrease; in other words, liquid was always deposited upon the hanging drop, no matter how often it was formed and drawn back. After a number of attempts to avoid this deposition upon the forming drop), by partially filling the cup with glass beads, sand, or filter paper, moistened with the liquid, and also by the use of a vertically placed bundle of short closed tubes, each filled with the liquid and presenting a meniscus of approximately the diameter of the drop itself, it was found that it could be avoided entirely by depositing the liquid (before the experiment) as a fog, upon the walls of the cup $D$. This fog can be produced very readily by heating the cup in a waterbath (after the apparatus has been set up and filled) $10^{\circ}$ to $20^{\circ}$. In this way minute drops of the liquid are deposited upon the walls of the cup, and change the condition within, so that there is then neither evaporation from the hanging drop, nor deposition upon it, and the upper meniscus always returns to the same point, no matter how often the drop may be formed and drawn back. Before each measurement we assured ourselves, in this way, that such a condition was attained.

It will be seen that the delicacy of this method depends simply upon the size of the capillary tubing used as the burette. Tube 3 ( $\mathrm{Imm}$. $=0.000,056$ cc.) was the smallest tubing available at the time, except, of course, the 
very narrow thermometer tubing, which offered too great a resistance to the flow of liquids, for our purposes. ${ }^{1}$

In all cases the apparatus was immersed in a waterbath with transparent sides, the temperature of which was kept constant to the point within $0 . I^{\circ}$.

\section{Results.}

In Tables I, II, and III are given our results for drop volumes and drop weights, and the relation observed between drop weight and surface ten-

TABLE I.

Diameter of tip $=0.622 \mathrm{~cm}$. approximately. I mm. on burtte $=0.0003 \mathrm{cc}$.

\begin{tabular}{|c|c|c|c|c|c|c|c|c|}
\hline \multirow[b]{2}{*}{ Substance. } & \multicolumn{2}{|c|}{$\begin{array}{c}\text { Surface } \\
\text { tension, } \\
\text { dynes per cm. }\end{array}$} & \multicolumn{3}{|c|}{ Weights of drop in mas. } & \multicolumn{3}{|c|}{$\frac{\text { Weight }}{\text { Surface }} \frac{\text { of drop }}{\text { tension }}=\frac{w}{\gamma}$} \\
\hline & Temp. & $\gamma$ & WP.D. & $W_{F . D .}$ & Wc.D. & $K_{\text {P.D. }}$ & $K_{\text {F.D. }}$ & $\mathrm{K}_{\mathrm{C} . \mathrm{D}}$ \\
\hline Ether... & 20.0 & 16.80 & & & 13.2 & 2.06 & I. 27 & 0.79 \\
\hline Benzene. & 22.5 & $29 \cdot 3^{8}$ & & & 6 & .91 & & .71 \\
\hline Ethy & Ig. I & 30.00 & & 3 & 7.2 & .77 & 0 & .57 \\
\hline Chlo & 20.0 & 32.10 & & 41.4 & 4.6 & .05 & I. 30 & 0.77 \\
\hline Guai & 19.6 & $37 \cdot 35$ & 78.5 & & & 10 & {$[\mathrm{I}$. } & 0.76 \\
\hline Benz & 15.4 & & & & & & & .71 \\
\hline Ani & I $7 \cdot 5$ & 44. I0 & & & 8.7 & & .21 & .65 \\
\hline Quir & I $5 \cdot 4$ & 45 . & & & .6 & & I & 0.65 \\
\hline Water... . . . . . . & 20.0 & 70.60 & 127.1 & 89.1 & $37 \cdot 5$ & 1.80 & I. 26 & 0.53 \\
\hline
\end{tabular}

Average $\mathrm{K}_{\mathrm{F} . \mathrm{D} .}=1.248 \pm 0.012$

Mean error of a single result $= \pm 0.035$

TABLE II.

Diameter of tip $=0.62 \mathrm{~cm}$. approximately. I mm. on burette $=0.00,008 \mathrm{cc}$.

\begin{tabular}{|c|c|c|c|c|c|c|}
\hline Substance. & Temp. & $\begin{array}{l}\text { Volume of } \\
\text { falling drop, } \\
\text { cc. }\end{array}$ & $\begin{array}{l}\text { Specific } \\
\text { gravity. }\end{array}$ & $\begin{array}{c}\text { falling drop } \\
\text { in mgs. } \\
\text { WF.D. }\end{array}$ & $\begin{array}{c}\text { surace ten- } \\
\text { sion, dynes } \\
\text { per. } \\
\gamma\end{array}$ & $K_{F, D,}=\frac{W_{F, I}}{\gamma}$ \\
\hline enzene. . & 30.5 & 0.03880 & 0.867 & 33.64 & 26.58 & I. 260 \\
\hline$\ldots \ldots$ & 60.7 & 0.03420 & 0.833 & 28.50 & 22.77 & I. 25I \\
\hline lorbenzene. . & 28.5 & $0.0356 \mathrm{I}$ & I.098 & 39.10 & 31.02 & I. $26 \mathrm{I}$ \\
\hline “ & 65.0 & 0.03220 & I.058 & 34.07 & $26.9 I$ & x. 266 \\
\hline Aniline. & 27.8 & 0.05033 & 1.013 & 50.99 & 40.69 & I. 250 \\
\hline & 58.2 & 0.04675 & 0.982 & $45.9 \mathrm{I}$ & $37 \cdot 32$ & 1.230 \\
\hline Quinoline. . & 28.0 & 0.04912 & 1.091 & $53 \cdot 58$ & $42 \cdot 30$ & I. 265 \\
\hline & 65.0 & 0.04572 & 1.060 & 48.47 & 38.22 & I. 268 \\
\hline Jater....... & $25 \cdot 5$ & $0.088 \times 2$ & 0.9969 & 87.85 & 69.70 & 1.260 \\
\hline & 56.9 & 0.08180 & 0.9848 & 80.55 & 64.79 & I. 244 \\
\hline$\ldots \ldots \ldots$ & 79.2 & 0.07742 & 0.9722 & $75 \cdot 20$ & 60.97 & I. 233 \\
\hline
\end{tabular}

Average $K_{\text {F.D. }}=1,253 \pm 0.004$

Mean error of a single result $= \pm 0.013$

1 It has since been possible to obtain still smaller tubing, and the work is now being continued in this laboratory with a burette on which I millimeter corresponds to about $0.000,046 \mathrm{cc}$.

${ }^{2}$ Commercial and impure; omitted in computing the average. 


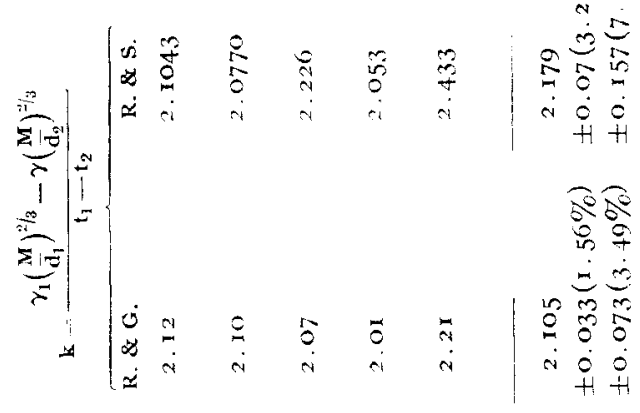

$\|$

$\stackrel{ \pm}{ \pm}$

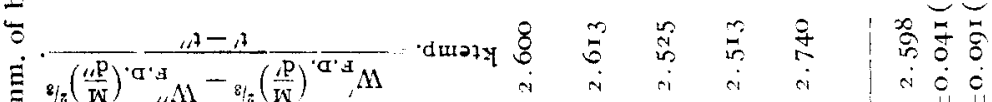

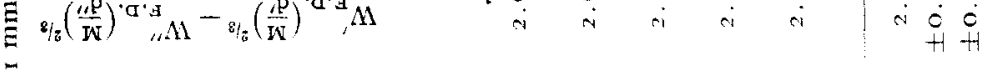

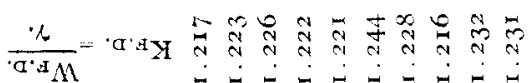

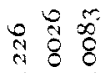

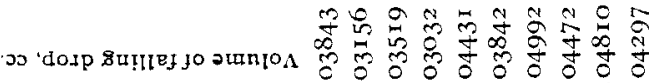

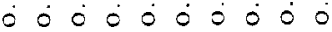
$\infty \pi n$ an

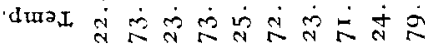


sion, together with the data necessary for the calculations. The surface tensions given, except those for water, are interpolated from the resultsdetermined under the same conditions as our drop weights, $i_{\text {. }} e_{\text {. }}$, against saturated air-of Renard and Guye, ${ }^{1}$ those for water being interpolated from the results of Ramsay and Shields, ${ }^{2}$ against the vapor pressure of the liquid. $\mathrm{K}_{\text {P.D. }}, \mathrm{K}_{\mathrm{F.D} \text {. }}$, and $\mathrm{K}_{\mathrm{C.D} \text {. }}$, in Table I, and $\mathrm{K}_{\mathrm{F} . \mathrm{D} \text {. }}$ in Tables II and III, are the factors by which the surface tension in dynes must be multiplied to give the drop weight, in milligrams, from these tips. $K_{F . D .}$ is the constant already mentioned in the real analytical expression of Tate's laws, when the same tip is employed. The tips used in Tables I, II, and III, although made from the same tubing, have slightly different diameters exposed, owing to the bevels being cut at slightly different angles. The diameter of the tubing itself was about 6.5 millimeters.

Table I shows our reason for determining the weight of only the falling drop with the more delicate form of apparatus.

In order that errors in our interpolations of the values of surface tension, as well as possible errors in the surface tensions themselves, might not influence our conclusions as to the accuracy of Tate's laws, in Table III, where the determinations are the most accurate, we have also secured a check, without any direct comparison with surface tension, by substituting our drop weights, of the same liquid at two different temperatures, for the surface tensions in the well-known law of Ramsay and Shields, and then comparing the constancy, for the various liquids, of our constant, $k_{\text {temp. }}$ with that of those of Ramsay and Shields, $\left(k_{\mathrm{R} . \& \mathrm{~s}}\right)$ and Renard and

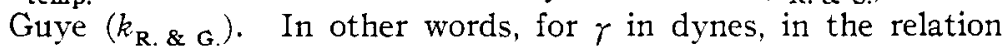

$$
\frac{\gamma_{1}\left(\frac{M}{d_{1}}\right)^{2 / 3}-\gamma_{2}\left(\frac{M}{d_{2}}\right)^{2 / 3}}{t_{1}-t_{2}}=k=2.12 \mathrm{ergs}^{3}
$$

we have substituted $W_{\text {F.D. }}$ in milligrams, so that if surface tension (as altered by temperature) and falling drop weight are proportional, for any one liquid from the same tip, we should find the expression

$$
W_{\text {F.D. }}^{\prime}\left(\frac{M}{d^{\prime}}\right)^{2 / 3}-\dot{W}_{\text {F.D. }}^{\prime \prime}\left(\frac{M}{d^{\prime \prime}}\right)^{2 / 3}=k_{\text {temp. }}
$$

just as constant as the other for all so-called "non-associated" liquids.

All our densities are interpolated from results found in the literature, as were also those of both Ramsay and Shields, and nenard and Guye, so that uniformity in the compared results is thus secu 1 .

All chemicals, with the exception of guaiacol (Ta' : I), which was impure, were specially purified for the purpose.

${ }^{1} \mathrm{~J}$. chim. phys., 5, 81 (1907).

2 Z. physik. Chem., 12, 43 I (1893).

$M$ is here the molecular weight as a liquid, $d$ the density, and $t$ the temperature. 
Our drop volumes throughout are each the average of several determinations, the extreme variation in tube 3 (Table III) being $0.2-0.4$ per cent.

TABLE IV.

Drop weights for various tip diameters. $t=27^{\circ}$.

\begin{tabular}{|c|c|c|c|c|c|c|}
\hline \multirow[b]{2}{*}{ Substance. } & \multicolumn{3}{|c|}{$W_{F . D .}$ in mgs. } & \multicolumn{3}{|c|}{$\mathrm{K}^{\prime}=\frac{W_{F, D}}{\mathrm{D} .}$} \\
\hline & $D_{1}=4.68 \mathrm{~mm}$ & $\mathrm{D}_{2}=6.22$ & $\mathrm{D}_{3}=7,12$ & $D_{1}$ & $\mathrm{D}_{2}$ & $\mathrm{D}_{3}$ \\
\hline Benzene.... & . 26.10 & 34.60 & 39.15 & 5.577 & $5 \cdot 5^{63}$ & 5.498 \\
\hline Chlorbenzene. & . . 29.70 & $40 \cdot 40$ & $45 \cdot 10$ & 6.348 & 6.495 & 6.190 \\
\hline Quinoline.... & $\ldots 41.15$ & 55.00 & 62.40 & 8.792 & 8.843 & 8.764 \\
\hline
\end{tabular}

In Table IV are given the drop weights issuing from beveled tips of various diameters. These results are not as accurate as some of the others, for tube 2 was used as the burette, and the error in measuring the lower end of the bevel is necessarily large. Under $\mathrm{K}^{\prime}$ are the values of the constant of Tate's first law, $i$. e., weight of falling drop divided by the diameter of the tip.

\section{TABLE V.}

$K_{\text {F.D. }}\left(=\frac{W_{\text {F.D. }}}{\gamma}\right)$ for tips ${ }^{1}$ of various forms.

\begin{tabular}{|c|c|c|c|c|c|c|c|}
\hline \multirow[b]{2}{*}{ Substance. } & \multirow[b]{2}{*}{ Temp. } & \multicolumn{2}{|l|}{ Rounded tip. } & \multirow{2}{*}{$\begin{array}{l}\text { Bevel at } 30^{\circ} \\
B^{\prime} \text { in Fig. } 3 .\end{array}$} & \multicolumn{2}{|c|}{ Sharpened edg } & \multirow{2}{*}{$\begin{array}{l}\text { Approx- } \\
\text { imate } \\
\text { surface } \\
\text { tensions }\end{array}$} \\
\hline & & $A$ in Fig. 3 & Temp. & & Teup. & $C$ in Fig. 3 & \\
\hline Alcohol.... & 58.4 & 0.907 & 60.1 & 1.070 & $\ldots$ & $\ldots$ & I9 \\
\hline & $21 \cdot 5$ & 0.934 & 225 & 1.090 & $2 \mathrm{I} \cdot \mathrm{I}$ & 1.123 & 22 \\
\hline Benzene. . & $\ldots$ & $\ldots$ & 65.0 & 1. I19 & $\ldots$ & $\ldots$ & $2 I$ \\
\hline & $\ldots$ & $\ldots$ & $22 . \mathrm{I}$ & I. 127 & $\ldots$ & $\ldots$ & 29 \\
\hline Chlorbenzene & 64.0 & 0.932 & 67.9 & I. 109 & $\ldots$ & & 27 \\
\hline & 22.5 & 0.965 & 24.0 & 1. 129 & 22.0 & 1.145 & 32 \\
\hline Quinoline. . & 64.0 & 0.124 & 72.0 & I. I 64 & $\ldots$ & $\ldots$ & 38 \\
\hline & $2 \mathrm{I} .0$ & 1.041 & 22.6 & I. 189 & 22.6 & I. 157 & 43 \\
\hline Water..... & $23 \cdot I$ & 1.080 & $25 \cdot 5$ & 1.220 & $2 \mathrm{I}, \mathrm{O}$ & I. 155 & 72 \\
\hline Average.... & & $0.983+$ & 25 & I. I $35 \pm$ & 017 & I. $145 \pm$ & 0.008 \\
\hline
\end{tabular}

Table $\mathrm{V}$ gives the results obtained by use of tips of various forms, but of approximately the same diameter (see Fig. 3). Tip $A$, here, is rounded at the end, $B$ has a bevel at an angle of about $30^{\circ}$, not sufficient to have

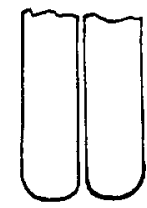

A

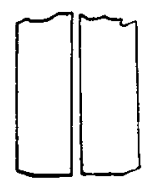

B

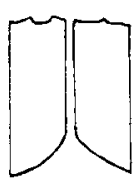

C

Fig. is.

1 Approximately of same diameter. 
the effect of a sharp edge, and $C$, without bevel, has a very sharp edge. All these were measured in tube 2 , and consequently the determinations are not as accurate as those in Table III.

Table Vi.-Critical, Temperatures. ${ }^{1}$

\begin{tabular}{|c|c|c|c|c|}
\hline \multirow[b]{2}{*}{ Substance. } & $\begin{array}{l}\text { From } \\
(\mathrm{M})^{2 / 3}\end{array}$ & $\gamma\left(\frac{M}{g}\right)^{2 / 3}=$ & $t-d)$ & \\
\hline & $W_{\text {F.D. }}\left(\frac{1}{d}\right)^{73}=k_{\text {temp. }}{ }^{(t-6)}$ & R. \& G.2 & R. \& S. ${ }^{3}$ & Observed. \\
\hline Benzene. & $\ldots 286.6$ & $285.8-289.6$ & 288 & $280.6-296.4$ \\
\hline Chlorbenzene. & $354 \cdot 1$ & $357 \cdot 2-35^{8} \cdot 4$ & $359 \cdot 7$ & $360.0-362.2$ \\
\hline Pyridine..... & 352.0 & $344 \cdot 7-346.9$ & 342 & $\ldots$ \\
\hline Aniline.... & $439 \cdot 4$ & $448.1-449 . I$ & $404 \cdot 9$ & $425 \cdot 7$ \\
\hline Quinoline. . & $\ldots \ldots \ldots 492 \cdot 3$ & $495.6-496.9$ & 466.1 & $<520$ \\
\hline
\end{tabular}

And, finally, in Table VI, are the critical temperatures of the liquids in Table III, as calculated by the substitution of the drop weight, $W_{\text {F.D. }}$, and $k_{\text {temp. }}$ for the surface tension $\gamma$, and $k$ in the Ramsay and Shields relation,

$$
\gamma\left(\frac{M}{d}\right)^{2 / 3}=(\tau-6)
$$

where $\tau$ is the difference between the critical temperature and that of observation, and $M, d$ and $k$ have the same meaning as before.

\section{Discussion of Results.}

It will be seen, even from Table I, where the experimental error in drop weight is comparatively large, that ,contrary to the conclusion of Guye and Perrot, the relationship between drop weight, from a properly constructed tip, and surface tension in saturated air, ${ }^{4}$ is very much more than a first approximation, even when the liquids examined include that giving the highest, and that giving almost the lowest, surface tension known, $i$. e., water at 70.6 and ether at $\mathbf{I} 6.8$ dynes per centimeter.

The results in Table II make this conclusion even more striking, for they show that much of the variation in $I$ is due to experimental error. And, finally, Table III, where the accuracy in the determination of drop volume and drop weight was the greatest possible at the time, shows the variation in the constant relationship, for some of the same liquids examined in I and II, to be very small indeed. Here, with five liquids, ${ }^{5}$ varying in surface tension from 25.88 to 52.62 dynes, each being studied

${ }^{1}$ Here, in all cases, the temperature coefficient ( $k$ or $k$ temp.) used is the one found for the specific liquid, and not the average values.

${ }^{2}$ Calculated extremes from surface tensions.

${ }^{3}$ Given by Ramsay and Shields, Loc. cit.

- According to Renard and Guye, surface tensions in saturated air and those under the vapor pressure of the liquid do not differ by more than 0.5 per cent.

- Unfortunately, ether could not be used in either tube 2 or tube 3 , owing to interference of a bulb; and the volume of tube 3 was too small to permit water to be used with the beveled tip. 


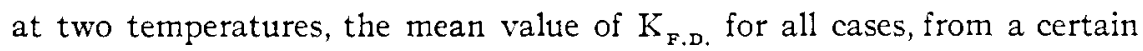
tip, is $1.226 \pm 0.0026$, the mean error of a single result being \pm 0.0083 .

Although in these results the error is small, the discrepancy is still too great-granting the accuracy of the drop weights and surface tensions-to conclude that the proportionality is rigidly exact; even though the agreement is about as good as that observed in results for surface tensions by different methods, and little worse than that shown in the results by any one method, by different observers. The error in drop weight cannot in any case exceed 0.4 per cent., taking all things into consideration, and is generally much less, consequently the discrepancy is only to be explained either by errors in the interpolated surface tensions, or by actual failure of the law of proportionality to hold closer than this (due possibly to a very slight and variable, but unnoticeable, rise of the liquids on the walls of the tip). When it is remembered, however, that the interpolations of the values for surface tension were made from smoothed curves, which could not always be made to pass through all the few points available, it becomes very apparent that in some cases errors in our interpolated surface tensions even as high as one per cent., are quite possible. If this be true, the law of the proportionality between falling drop weight (from a proper tip) and surface tension becomes rigid. To prove this directly and conclusively has been impossible, for it could be done only by aid of a more delicate apparatus, with measurements of drop weights at the exact temperatures at which the surface tensions themselves have been determined. ${ }^{1}$ Below, however, it is shown that the interpolated values of surface tension for any one liquid are burdened with error, so that analogy would force the conclusion that they, also, are at the root of the error when different liquids are considered.

We would conclude, then, from Tables I, II, and III, and from the behavior of $\operatorname{tip} C$ in Table $V$, that Tate's second law-the weight of a falling drop (from a proper tip) is proportional to the surface tension (against saturated air) of the liquid-is true. Because surface tensions calculated from drop weights agree, even with those possibly faultily interpolated from results by capillary rise, as well as those determined by other methods agree with these, when directly determined.

Consideration of the columns $k_{\text {temp. }}, k_{\mathrm{R} . \& \mathrm{G} \text {, }}$ and $k_{\mathrm{K} . \& \mathrm{~s} \text {. }}$, in Table III, shows that our constants, though calculated from results at only two temperatures, are as constant as those of Renard and Guye, which are in each case the mean of determinations made at several pairs of temperatures, and are very much more constant than those of Ramsay and Shields, ${ }^{2}$ from

'This is now being done in this laboratory.

"Although Ramsay and Shields's values were calculated from surface tensions observed under different conditions, their constants are still to be compared with the others as to constancy. 
results at two temperatures. It will also be observed that the variation of $k_{\text {temp. }}$ from its mean value is always (when worth considering) in the same direction as that of Renard and Guye's, for the same liquid.

This certainly proves conclusively that, with any one liquid, from any one tip, drop weight is proportional to the surface tension, as it is altered by changes in temperature, for, by substitution of drop weight for surface tension in the Ramsay and Shields expression, leaving out any direct comparison with the interpolated values of surface tensions, a result is obtained which is as constant as that found by the use of directly determined-not interpolatedsurface tensions. And this is true when our interpolated values of surface tension at the two temperatures lead to a discrepancy in the two values of $K_{\text {F.D. }}$, as calculated for that liquid. Although this proof is not direct, as far as concerns different liquids, it leaves very little possibility of the slight discrepancy in $K_{\text {F.D. }}$ being due to anything but the errors in the interpolated surface tensions as we concluded above.

We would conclude from the constancy of $k_{\text {temp. }}$, in Table III, then:

That Tate's third law- the weight of a falling drop decreases with increased temperature-is true. And, further, that the change in drop weight for a change in temperature can be calculated accurately for nonassociated liquids, by the substitution of the drop weight at one temperature for the surface tension, and $k_{\text {temp. }}$ for $k$ in the Ramsay and Shields relation

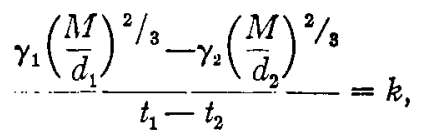

and solving for the other drop weight.

Or, knowing the drop weights, $k_{\text {temp, }}$, and the densities, it is possible to find the molecular weight of the liquid, with an accuracy equal to that attained when surface tensions are employed directly in the above relation.

Since the molecular temperature coefficient, $k_{\text {temp }}$, is found to be constant, it is possible, by extrapolation, to find the temperature at which the drop weight would become zero; $i$. e., the critical temperature of the liquid, for at that point the drop would disappear, there being then no distinction between the gas and the liquid. It is only necessary, for this calculation, to substitute $W_{\text {F.D. }}$ for $\gamma$ and $k_{\text {temp. }}$ for $k$, in the other form of the Ramsay and Shields relation, $i . e$,

$$
\gamma\left(\frac{M}{d}\right)^{2 / 3}=k(\tau-6),
$$

and solve for the critical temperature ( $\tau$ plus the temperature at which $\gamma$ (or $W_{\text {F.D. }}$ ) is determined). (See Table VI.)

It must be remembered here, however, that in all cases in which we have applied this method, we have done so at a disadvantage, for we have but 
two points through which to draw the eurve. Iiurther than that we have worked at low temperatures (never above $80^{\circ}$ ), and consequently must cxtrapolate from these two points through a much greater distance than either Renard and Guye, or Ramsay and Shields, from their larger number. The first objection holds for all our liquids, though least for benzene, but the second hardly affects benzene, for $73.2^{\circ}$ is not far from its boiling-point. With all high-boiling liquids, both objections hold, and both increase with the boiling point (and critical temperature).

From the equal constancy of $k_{\text {temp. }}$. and $k$, howerer, it is evident that just as accurate critical temperatures can be calculated from drop weights as from surface tensions, against saturated air, provided in both cases the determinations, from which the molecular temperature coefficients are found, arc made at as many temporatures, and carried to as high a temperature.

Table IV, it is thought, shows that from such tips, between these diameters, there is a direct proportionality between drop weight and diameter of the tip (Tate's first law). At least there is no decided trend in the proportional factor, for it varies just as one might expect it to from the known, and fairly large, experimental error. It must be remembered that tips larger than the diameter of the maximum drop would always deliver one constant maximum drop weight; while, when the tip becomes small, there is probably a point beyond which the drop will not decrease appreciably in weight for a considerable change in diameter, for it would then be difficult to prevent in any way the rise of liquid upon walls of the tip.

Table $V$ shows that when rounded, a tip behaves differently from the one in Table III; the liquid rises to various heights on the outer walls, and the diameter of the basis for the drop varies with the nature of the liquid. This is also true, though to a lesser degree, with the tube that is insufficiently beveled. In neither case is $K_{\mathrm{H}, \mathrm{D}}$. even approximately constant. Tip $C$, on the other hand, compares very favorably with the other beveled one, used with Tube 2 ('Table II). Whatever theory may be advanced, then, as to the tip, it will be seen that the point to be considered is the effect of the tip ('Tate's "sharp edge") in delimiting the portion upon which the drop can hang, especially by preventing the rise of liquid upon the walls, for that would be variable with different liquids, and lead to variable weights. Undoubtedly it is only the failure to follow Tate's directions in this respect that has caused the determinations of drop weights, since his time, to negative his conclusions.

\section{Summary.}

The results of this investigation may be summarized as follows:

I. An apparatus is described by which it is possible to make a very accurate estimation of the volume of a single drop of liquid falling from a tube, and consequently of its weight. 
2. With this apparatus was used a capillary tip, beveled at an angle of $45^{\circ}$, which, contrary to those used by other investigators, had the same effect as the one originally used by Tate, $i . e_{.}$, it delimits the area of the tip wetted, by preventing the rise of liquid upon the walls, and thus forces all liquids to drop from one and the same area.

3. It is shown that whenever this effect is obtained, either by use of a properly beveled tube, or one ground to a sharp edge, the drop weight has a different meaning than it has when the drop is formed on either a rounded tip, or on one insufficiently beveled.

4. The falling drop from a capillary tip, and not the pendant drop, is proportional in weight to that of the falling drop from a thin-walled tube with a sharp edge.

5. From such tips as we have used, it is concluded that Tate's second law-the weight of a drop, other things being the same, is proportional to the surface tension (against saturated air) of the liquid-is true.

6. It is shown that from such a tip, Tate's third law-the weight of a drop is decreased by an increase in temperature-is true.

7. Falling drop weights for the same liquid at two temperatures, from such a tip, can be substituted for the surface tensions in the relation of Ramsay and Shields, and molecular weights in the liquid state calculated with an accuracy equal to that possible by aid of surface tensions, under the same, saturated air, conditions. And, by aid of this formula, knowing the molecular weight of a non-associated liquid, the falling drop weight at one temperature, and the densities, it is possible to calculate the weight of the drop falling from the same tip at another temperature.

8. Critical temperatures can be calculated by aid of Ramsay and Shields's equation $\gamma\left(\frac{M}{d}\right)^{2 / 3}=k(\tau-6)$, by substituting a drop weight for surface tension, and the molecular temperature coefficient of drop weight for $k$, with the same accuracy attained by the use of surface tensions (against saturated air), provided the drop weights (from which the coefficient is found) are determined at as many temperatures, and at as high a temperature as the surface tensions.

9. For beveled tips, when the diameters lie between 4.68 and $7.12 \mathrm{~mm}$, Tate's first law-the drop weight of any one liquid is proportional, under like conditions, to the diameter of the dropping tube-is true.

BIBLIOGRAPHY OF DROP WEIGHT-ALPHABETICALIY ARRANGED.

Autonow, G. N.

Bolle, J,

Duclaux.

Dupré.

Eschbaum, F.

Guglieimo, G.

Guthrie.

Guye and Perrot.
J. chim. phys., 5, 372 (1907).

Geneva Dissertation, 1902.

Ann. chim. phys., 4th ser., 2I, 386 (1870).

Ibrd., 9, 345 (1866).

Ber. pharm. Ges., Heft 4, 1900.

Accad. Lincei Atti., 12, 462 (1904); 15, 287 (1906).

Proc. Roy. Soc., 13, 444 (1864).

Arch. scien. phys, et naturelle, 4th ser., rr, 225 (1901); 4th ser., 15, 31 2 (1903). 
Hagen.

Hannay, J. B.

Kohlrausch, F

Lebaigue.

Leduc and Larcdote.

Lohnstein, F.

Mathieu.

Ollivier.

Rayleigh.

Rosset.

Tate, $\mathrm{T}$.

Traube.

Volkmann, $P$.

Worthington.
Berl. Akad., 78, 1845 .

Proc. Roy. Soc. Edin., 437, 1905.

Ann. phys., 20, 798 (1906); 22, 191 (1907).

J. pharm. chim., 7, 87 (1868).

J. phys., $\mathrm{r}, 36+$ and 716 (1902).

C. r., I34, 589; I35, 95 and 732 (1902).

Ann. phys., 20, 237 and $606 ; 2$ I, 1030 (1906); 22, 737 (1907).

J. phys. [2], 3, 20,3 (1884).

Ann. chim. phys., 8th ser., 10, 229 (1907).

Phil.Mag., jth ser., 20, 32 I (1899).

Bull. soc. chim., 23, 245 (1900).

Phil. Mag., 27, I76 (1864).

J. pr. Chem. [2],34,292 and $515(1886)$.

Ber., I9, 874 (I886).

Ann. physik. (2), II, 200.

Proc. Roy. Soc., 32, 362 (1881).

Phil.Mag., 5th ser., I 8, 46r (1884); I9, 46 (1885); 20, 5 I (I 885 ).

LABORATORY OF PHYSICAL CAEMISTRY,

December, 1907 .

\section{THE ACTION OF HYDROGEN SULPHIDE ON ALKALINE SOLUTIONS OF ZINC SALTS.}

IiY I. W. MCCAY.

Received December 23, 190\%.

The fact that the zinc sulphide, or the zinc hydrosulphide, precipitated from alkaline solutions of zinc salts by sodium or potassium hydrosulphide is soluble in an excess of these reagents, and that the zinc sulphide, or zinc hydrosulphide, precipitated from alkaline solutions of the metal by hydrogen sulphide dissolves when the gas is permitted to act on the solutions for some time, appears to have escaped the notice of the analytical chemists. ${ }^{1}$ At all events, in no work on analytical chemistry to which I have access is this remarkable behavior of zinc sulphide referred to. The solution of the zinc sulphide is a colloidal one, for the zinc in it will not pass through parchment paper. The zinc sulphide, or zinc hydrosulphide, acts towards sodium and potassium hydrosulphides in much the same way that zinc oxide, or zinc hydroxide, acts towards sodium and potassium hydroxides. The analogy between the two reactions almost compels one to conclude that the change takes place in the sense of the equation:

$$
\mathrm{Zn}(\mathrm{SH})_{2}+2 \mathrm{RSH}=\mathrm{R}_{2} \mathrm{ZnS}_{2}+2 \mathrm{H}_{2} \mathrm{~S} \text {. }
$$

If, however, an alkali sulphozincate is actually formed, it must be very unstable, for concentrated solutions of mineral salts, when added to its solution, precipitate only zinc sulphide, or possibly zinc hydrosulphide;

'I noticed this peculiar behavior of zinc sulphide some three or four years ago and supposed that my observation was a new one. I found, however, that the reaction was first observed by Julius Thomsen in 1878 (Ber., Ir, 2044) and subsequently examined by A. Villiers (Compt. rend., r20, 97). Lottermoser (Samlung chem. u. tech. Vorträge, VI) und Winsinger (Bull. de l'Acad. des Sciences de Bruxelles, [2], 14, 32I) also tefer to it. 